\title{
O QUE FONOAUDIÓLOGOS E ESTUDANTES DE FONOAUDIOLOGIA ENTENDEM POR FLUÊNCIA E DISFLUÊNCIA
}

\section{What speech-language pathologists and students of speech- pathology understand as fluency and disfluency}

\author{
Ana Maria do Carmo Carvalho de Oliveira ${ }^{(1)}$, Ignês Maia Ribeiro ${ }^{(2)}$, \\ Sandra Merlo ${ }^{(3)}$, Ana Lúcia de Magalhães Leal Chiappetta ${ }^{(4)}$
}

\begin{abstract}
RESUMO
Objetivo: verificar a compreensão dos estudantes de $3^{\circ}$ e $4^{\circ}$ anos e dos profissionais de Fonoaudiologia em relação aos conceitos de fluência e disfluência, aos componentes e influenciadores da fluência e aos tipos de disfluências. Métodos: foram aplicados 107 questionários a uma amostra de 57 profissionais e 50 estudantes. Foi realizada análise qualitativo-quantitativa das questões abertas e quantitativa das questões fechadas. Resultados: a análise descritiva identificou mais de 20 fatores para as perguntas abertas (conceito de fluência e de disfluência e componentes da fluência), mas nenhum fator citado pela maioria dos sujeitos. O componente da fluência mais listado relaciona-se à taxa de elocução. Fatores psicológicos como ansiedade e introversão-extroversão estão entre os fatores mais citados como influenciadores do grau de fluência. Os tipos de disfluências mais categorizadas como gaguejadas foram bloqueios, prolongamentos iniciais e comportamentos de defesa. Não houve diferença estatisticamente significante entre profissionais e estudantes quanto ao perfil de respostas. $O$ aumento dos anos de atuação modificou algumas respostas. Conclusão: os participantes: 1) apresentaram conceito idealizado de fluência ("fala livre de rupturas"), 2) consideraram disfluência como sinal de alteração e não como um fenômeno intrínseco da fala, 3) consideraram a taxa de elocução, e não as disfluências, como o componente que mais afeta o grau de fluência, 4) consideraram os fatores afetivos, principalmente a ansiedade, como os que mais influenciam o grau de fluência, atribuindo uma influência secundária a fatores lingüísticos, cognitivos e genéticos e 5) classificaram os tipos de disfluências de maneira alinhada com a literatura.
\end{abstract}

DESCRITORES: Linguagem; Gagueira; Formação de Conceito; Prática Profissional

\section{INTRODUÇÃO}

A gagueira tem sido comumente classificada como sendo uma ruptura involuntária do fluxo natural de fala ${ }^{1}$ ou uma perturbação da fluência ${ }^{2}$. Se o aspecto mais

(1) Fonoaudióloga; Biofono Clínicia de Fonoaudiologia; Especialista em Linguagem.

(2) Fonoaudióloga; Diretora Presidente do Instituto Brasileiro de Fluência; Especialista em Linguagem; Mestre em Distúrbios da Comunicação pela Pontifícia Universidade Católica de São Paulo.

(3) Fonoaudióloga; Diretora Científica do Instituto Brasileiro de Fluência; Mestre em Lingüística (Fonética/Fonologia) pela Universidade Estadual de Campinas.

(4) Fonoaudióloga Responsável pelo Setor de Investigação em Doenças Neuromusculares da Universidade Federal de São Paulo; Doutora em Ciências pela Universidade Federal de São Paulo. marcante desse distúrbio é o desvio da fluência, é necessário compreender o que caracteriza a fluência tida como normal, incluindo a compreensão do papel das disfluências ${ }^{3}$. A compreensão mais aprofundada da fluência como um todo permite, também, caracterizar melhor o contínuo entre "normal" e "patológico".

Ao buscar conceitos de fluência na literatura encontra-se pouco consenso. Muitas vezes a fluência é descrita como uma habilidade para manter o fluxo contínuo de fala ${ }^{4}$, o que indica a ausência de descontinuidades, rupturas ou disfluências ${ }^{5}$. Alguns autores compreendem a fluência como uma habilidade lingüística ${ }^{6,7}$, ou seja, uma capacidade adquirida com a prática do uso da língua em diferentes contextos de fala, o que promove o desenvolvimento de mecanismos automáticos de processamento ${ }^{8}$, sem desconsiderar que quebras e interrupções são constituintes da fluência ${ }^{9}$. 
Por outro lado, encontra-se consenso na literatura em relação ao conceito de disfluência na medida em que é tida como um fenômeno que marca descontinuidades no fluxo de fala, pois é comum encontrá-la descrita por meio de expressões como: quebra $^{10-12}$, ruptura ${ }^{2,10,11,13}$, interrupção ${ }^{2,14}$, rompimento ${ }^{6,15}$ ou impedimento ${ }^{16}$ da fluência. Apesar da disfluência não necessariamente ser uma anormalidade da fala, ainda é possível encontrar o termo sendo utilizado como sinônimo de gagueira ${ }^{2,17}$. A disfluência é uma interrupção temporária que pode ocorrer durante a construção do texto falado, sendo uma ocorrência comum na fala de todos os indivíduos ${ }^{6,12,15}$, desempenhando papéis interacionais e cognitivos (planejamento e/ou verbalização) no processo de construção do texto ${ }^{18}$.

A fluência é um fenômeno multifacetado, por isso freqüentemente alguns autores salientam que é composta por diversos elementos. Além das próprias disfluências, estão entre os mais citados na literatura: o esforço/tensão ${ }^{3,19-22}$ despendido pelo falante para executar a atividade motora e o processamento cognitivo-lingüístico, manifestando o quanto essa execução é fácil, confortável ou perturbadora para o falante; a taxa de elocução ${ }^{7}$ ("velocidade da fala"), geralmente mensurada nas avaliações de fluênciapor encontrar-se alterada nos seus distúrbios ${ }^{11,21} \mathrm{e}$ as pausas silenciosas características do uso nativo da língua e que, na fala fluente, costumam apresentar baixa freqüência e curta duração ${ }^{7,8}$.

A fluência não é um aspecto estático da fala: ela se manifesta em contextos reais de interação e por isso pode ser afetada por uma série de fatores. Muitas pesquisas têm investigado essa relação, porém ainda não é possível precisar com exatidão o que afetaria mais ou menos a fluência. Sabe-se que fatores lingüísticos, cognitivos, afetivos e genéticos afetam a fluência . Dentre os fatores lingüísticos, destacam-se o tipo textual (narrativas tendem a ser menos fluentes do que descrições ${ }^{23}$ ) e o tipo de língua (a fluência em língua materna é maior do que em segunda língua ou língua estrangeira ${ }^{8}$ ). Dentre os fatores cognitivos, destacam-se a idade (adultos tendem a ser mais fluentes do que crianças ${ }^{5}$ ) e a capacidade da memória operacional (sujeitos com alto span tendem a ser mais fluentes do que sujeitos com baixo span ${ }^{24}$ ). Dentre os fatores psicológicos, destaca-se um aspecto muito particular da ansiedade, o fenômeno de freezing (quanto maior o grau de freezing, menor o grau de fluência ${ }^{25}$ ). Dentre os fatores genéticos, destaca-se o sexo (mulheres tendem a ser mais fluentes do que homens ${ }^{4}$ ).

Há muitos anos, têm-se procurado uma classificação para as disfluências, dividindo-as em dois grupos: comum (normal, típica ou não-gaga) e gaguejada (gaga, atípica ou anormal). Freqüentemente as listas classificam como normais: repetição em nível da palavra (de palavras inteiras ou de sintagmas), falsos inícios corrigidos (revisões), falsos inícios abandonados ("frases incompletas"), pausas hesitativas ("hesitações"), pausas preenchidas ("interjeições") e prolongamentos finais ${ }^{2,7,11,13,14,26-28}$. As disfluências geralmente categorizadas como gagas são: repetições de parte de palavras (sílabas ou fones), bloqueios e prolongamentos iniciais ${ }^{2,11,13,14,26-29}$. Também tem sido consideradas características de gagueira os comportamentos acessórios ou concomitantes físicos associados à fala como: tensão corporal, fuga ou evitação de situações de fala ${ }^{27,28}$ e a consciência das disfluências como um problema a ser corrigido ou evitado ${ }^{30}$.

O objetivo deste trabalho é verificar a compreensão de estudantes de $3^{\circ}$. e $4^{\circ}$. anos e de profissionais da fonoaudiologia em relação aos conceitos de fluência e disfluência, os componentes e influenciadores da fluência e quais os tipos de disfluências são mais característicos da fala tida como normal.

\section{MÉTODOS}

No período de outubro a dezembro de 2005 foram distribuídos 250 questionários auto-aplicados, nos estados de São Paulo, Rio de Janeiro, Rio Grande do Sul, Goiás e Distrito Federal, acompanhados de carta de esclarecimento e o Termo de Consentimento Livre e Esclarecido. Desses retornaram 107 respondidos. O questionário era composto por cinco perguntas: três abertas ("O que é fluência para você?", "O que é disfluência para você?" e "Para você, quais são os componentes da fluência da linguagem oral, ou seja, o que compõe uma fala fluente?") e duas fechadas ("Dos fatores abaixo, assinale quais você considera que afetam a fluência da linguagem oral" e "Quais dos aspectos abaixo relacionados você considera como característica de disfluência normal (comum em falantes normais) e de disfluência gaga (mais típica de falantes gagos)?"). A amostra pesquisada compõe-se de profissionais e de estudantes de fonoaudiologia do $3^{\circ}$ e $4^{\circ}$. anos.

As respostas às questões abertas foram submetidas a uma análise qualitativo-quantitativa, recortando-se elementos que constituíram unidades de significado, montando-se, assim, fatores analíticos para posterior análise quantitativa. As questões de múltipla escolha foram analisadas conforme a marcação feita pelos sujeitos.

Esta pesquisa foi avaliada e aprovada pelo Comitê de Ética em Pesquisa do CEFAC - Saúde e Educação, sob o protocolo no. 120/05 que considerou sem risco e com necessidade do Termo de Consentimento Livre e Esclarecido.

Os dados foram submetidos à análise estatística descritiva e inferencial. Foram utilizados os testes de 
proporções, Kolmogorov-Smirnov e correlação Gamma, considerando-se como nível de significância $\alpha \leq 0,05$.

\section{RESULTADOS}

A amostra foi composta por 57 sujeitos profissionais e 50 estudantes, num total de 107 sujeitos, sendo $25 \%$ pós-graduados, $28 \%$ graduados e $45 \%$ estudantes. Quanto à atuação específica em distúrbios da fluência, $53 \%$ da amostra atende ou já atendeu casos de gagueira do desenvolvimento e $35,5 \%$ atende ou já atendeu outros casos de distúrbios da fluência. Quanto às áreas de atuação profissional, os sujeitos estão assim distribuídos: $34 \%$ atuam com Motricidade Orofacial, 28\% com Linguagem, 21\% com Voz e 9\% com Audiologia.

O teste Kolmogorov-Smirnov indicou que o número de profissionais que atende ou atendeu casos de gagueira era significativamente maior do que o número de estudantes com as mesmas características ( $p$ $<0.01$ ); sendo assim, não foi possível comparar se as respostas desses profissionais são significativamente difererentes das dos estudantes. Entretanto, profissionais e estudantes atendem ou atenderam igualmente outros distúrbios da fluência ( $p>0.10)$, sendo possível verificar se esse fato modifica suas respostas.

Com o recorte dos conteúdos das respostas abertas foram definidos os seguintes fatores analíticos: 23 fatores para conceito de fluência, 21 para conceito de disfluência e 20 para componentes da fluência (Figuras 1, 2 e 3). A análise estatística descritiva de tais fatores revelou um dado fundamental: a moda para todos os fatores é igual a zero, ou seja, nenhum fator foi citado pela maioria dos sujeitos da pesquisa como sendo tipicamente relacionado a nenhum dos aspectos analisados.

As respostas das questões fechadas (influenciadores da fluência e classificação das disfluências) podem ser visibilizados nas Figuras $4 \mathrm{e}$ 5 , respectivamente. Nestes casos, houve fatores tipicamente associados às variações de fluência e à classificação de determinadas disfluências como tipicamente gaguejadas, tendo em vista que diversos fatores apresentaram moda igual a um.

O teste Kolmogorov-Smirnov indicou não haver diferença estatisticamente significante $(p>0.10)$ entre profissionais e estudantes, nem entre quem atende/atendeu outros distúrbios da fluência (que não gagueira) em nenhum dos aspectos estudados.

O teste de Correlação Gamma indicou que os anos de atuação modificam, em parte, os resultados encontrados, aumentando a citação de: 1) "fala sem prolongamentos", "fala sem pausas", "fala eficiente", "fala sem hesitações" e "fluência relacionada à boa coordenação pneumo-fono-articulatória" para o conceito de fluência; 2) "pausas" e "alteração de inteligibilidade" para o conceito de disfluência; 3 ) "duração", "suavidade", "articulação", "seqüência" e "cognição" como componentes de fluência; 4) "repetição de frases" e "revisões" como disfluência atípica/ gaga. Além disso, o teste de Correlação Gamma indicou que os anos de atuação diminuem a citação de: 1) "fala sem quebras" e "fala sem bloqueios" para o conceito de fluência; 2) "alteração de fala" para o conceito de disfluência; 3 ) "sistema nervoso central" e "audição" como componentes da fluência; 4) "idade", "atenção", "ansiedade" e "imagem de falante" como aspectos que influenciam a fluência e 5) "prolongamento inicial" como disfluência atípica/gaga.

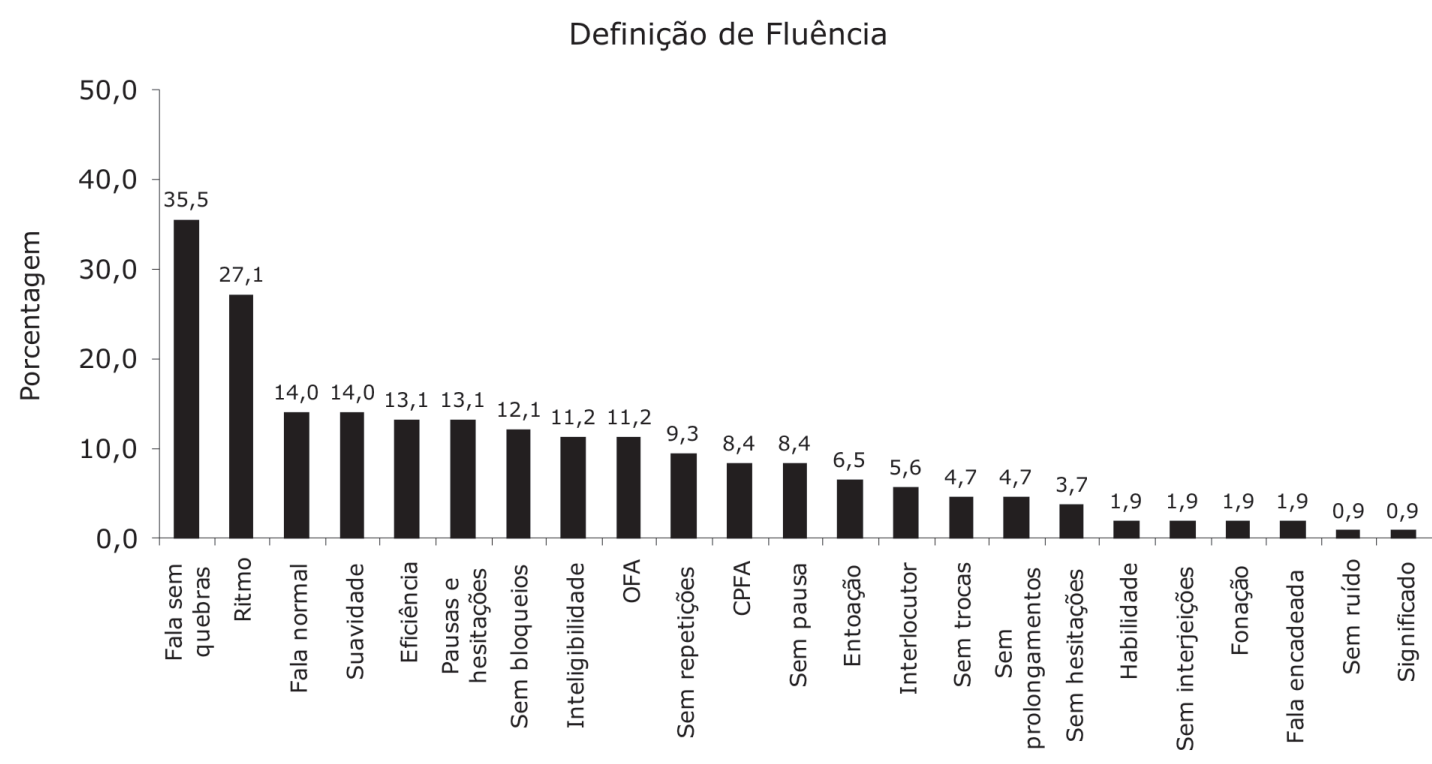

Figura 1 - Análise estatística descritiva da decomposição das respostas sobre fluência 


\section{DISCUSSÃO}

Tanto entre profissionais quanto entre estudantes, observou-se uma grande variedade de termos utilizados para conceituar fluência, conceituar disfluência e enumerar os componentes da fluência, sem a existência de um padrão típico de resposta. Isso pode ser um indício de que nem a formação acadêmica, nem a atuação profissional consolidaram esses conceitos. O fato de atender ou haver atendido casos de distúrbios da fluência, que não gagueira do desenvolvimento, não refinou a compreensão sobre esses fenômenos por parte dos sujeitos.

Quando se comparam os resultados apresentados nas Figuras 1 e 2 observa-se uma coincidência de conteúdo para quase todos os fatores analíticos e mais interessantemente na ordem com que se apresentam as três primeiras expressões (fala sem quebra/fala com quebra, fala sem alteração no ritmo/alteração no ritmo, fala normal/alteração na fala).

A maioria dos sujeitos procurou definir a fluência pela negativa, ou seja, indicando o que a fluência não é ao invés de indicar o que a fluência é, confirmando, assim, uma observação já presente na literatura ${ }^{5}$. O aumento dos anos de atuação na fonoaudiologia parece fortalecer a crença na existência de um falante ideal. Esse resultado parece paradoxal, porque seria esperado que, conforme ocorresse o aumento dos anos de atuação, fosse sendo derrubado o mito do falante ideal ${ }^{5}$, cedendo lugar a um falante real (que interrompe e hesita, fenômenos típicos e exclusivos da linguagem falada ${ }^{31}$ ).

A maioria dos sujeitos igualou disfluência a algum tipo de alteração (algumas relacionadas à fluência e outras não), talvez porque o objeto clássico de estudo da fonoaudiologia seja os distúrbios de comunicação e não a comunicação das pessoas comuns. Entretanto, conhecer as estruturas e os processos da comunicação de pessoas comuns é fundamental para saber diferir normalidade de patologia com algum grau de precisão. Também é interessante constatar que houve uma maior citação de termos como "quebra, ruptura, interrupção" para definir fluência do que para conceituar disfluência, porém, na literatura essas expressões foram freqüentemente encontradas nas definições de disfluência ${ }^{2,10-16}$. O aumento dos anos de atuação na fonoaudiologia contribuiu para distorcer ainda mais o conceito de disfluência de nossos sujeitos, tendo em vista que, conforme os anos de atuação aumentaram, aumentou a citação de que disfluência é igual à pausa.

As respostas sobre componentes da fluência evidenciaram que os sujeitos da pesquisa apre- sentaram dificuldades para nomear componentes específicos da fluência, tendo em vista que aproximadamente metade das respostas envolveu conceitos amplos ("articulação, entoação, cognição, sistema nervoso central") e algumas vezes nãorelacionados aos componentes da fluência ("audição, aspectos psicológicos"). O aumento dos anos de atuação na fonoaudiologia tendeu a aumentar o número de fatores citados como componentes da fluência; por um lado, reforçando o fator "suavidade" (tido como muito importante pela literatura ${ }^{3,7,8,11,12,19-22,32}$, mas, por outro lado, também aumentando a citação de fatores pouco relacionados com os componentes da fluência (como "articulação", "seqüência" e "cognição").

Nas respostas às questões sobre conceito de fluência, conceito de disfluência e componentes da fluência observou-se uma imprecisão com relação ao emprego de vocábulos como "ritmo, velocidade, duração, entoação, melodia, prosódia”. Em muitos momentos, esses termos pareciam empregados quase que indistintamente, o que evidencia que conhecimentos fundamentais da área de fonética, tidos como básicos para a fonoaudiologia, não foram suficientemente assimilados pelos sujeitos.

Chama a atenção o grande número de citações nas questões abertas para termos relacionados à taxa de elocução, por exemplo "ritmo" e "velocidade", sugerindo que, para os sujeitos da pesquisa, fluência e disfluência estão fortemente relacionadas a variações na taxa de elocução. Porém, não foram encontradas referências de que a taxa de elocução componha o conceito de fluência, entretanto, foram encontradas referências que indicam que a ocorrência da disfluência ocasiona uma desaceleração na construção do texto falado ${ }^{19}$ e também que a taxa de elocução é um dos componentes da fluência, porém, menos importante do que as disfluências ${ }^{8}$. Por outro lado esses termos estão presentes quase que sistematicamente nos textos de fonoaudiologia quando se faz referência a fluência no contexto da gagueira $3,11,21,22,33,34$.

A suavidade ou ausência de esforço foi pouco citada, em média por $16,8 \%$ dos sujeitos, nas quatro questões em que esse aspecto da fala foi mencionado ou relacionado, contrariando a visão da literatura que considera esse aspecto como primordial na caracterização de uma fala fluente $3,7,8,11,12,19-22,32$.

Um fato particularmente curioso é a marcação quase unânime da ansiedade como um influenciador da fluência. Apesar dessa ser uma característica freqüentemente atribuída a pessoas que gaguejam, não existem pesquisas sistematicamente elaboradas cujos dados comprovem 
essa relação ${ }^{35}$ e há uma controvérsia quanto a ser causa ou conseqüência ${ }^{25,37}$. Além disso, dos oito fatores citados pela maioria dos sujeitos como influenciadores na fluência, quatro fatores poderiam ser classificados como "afetivos/ psicológicos" (ansiedade, introversão-extroversão, imagem de falante e abuso de drogas). Entretanto, em um estudo cujo objetivo foi comparar a percepção de pais de crianças gagas e fluentes sobre as características de temperamento de seus filhos, não foi registrada diferença estatisticamente significante entre os dois grupos ${ }^{35}$.

Por outro lado, alguns fatores lingüísticos (como tipo de língua ${ }^{8}$, habilidade gramatical ${ }^{5} \mathrm{e}$ pausas ${ }^{79} 9,24$ ), cognitivos (memória operacional e de longo prazo ${ }^{24}$ ) e genéticos (como sexo ${ }^{4}$ ), que apresentam um maior número de evidências científicas em relação ao seu impacto na fluência foram citados por uma minoria de sujeitos. Um estudo sobre disfluência em crianças demonstrou que há uma maior ocorrência de hesitações quando elas tentam produzir enunciados sintática e semanticamente mais elaborados ou quando são pressionadas a emitir enunciados acima de sua capacidade lingüística ${ }^{38}$; outros dois estudos na língua espanhola demonstraram que a idade, a escolaridade e o rendimento cognitivo geral são fatores que influem nos testes de fluência verbal (semântica e fonológica) ${ }^{39,40}$. Ainda em outro estudo com 60 adultos fluentes verificou-se que apenas nos textos de tipo narrativa de temas pouco familiares houve aumento das hesitações ${ }^{23}$. Diante de tais evidências e do resultado encontrado neste estudo, parece que a amostra pesquisada está mais próxima do conhecimento comum do que do conhecimento científico da área de fluência e, apesar do aumento dos anos de atuação levar à diminuição da seleção de fatores afetivos, não se observa um aumento na ocorrência de fatores lingüísticos e cognitivos.

Quanto à classificação dos tipos de disfluência, de maneira geral, parece haver uma compreensão compatível com a encontrada na literatura tanto para as disfluências do tipo gaguejadas quanto para as do tipo comum ${ }^{2,11,13,14,26-}$ 30. Dois aspectos são particularmente interesantes: 1) não houve disfluência ou comportamento classificados pelos sujeitos como sendo exclusivos da fala comum ou da fala gaguejada e 2) os profissionais com maior tempo de atuação tenderam a aumentar a citação de repetições de sintagmas/"frases" e revisões como disfluências gagas. Apesar de os sujeitos indicarem que compreendem que determinadas disfluências e determinados comportamentos tendem a ser mais tipicamente encontrados em su- jeitos com gagueira, eles também parece evidenciar a percepção de que, por trás de uma disfluência comum, pode estar o uso voluntário da disfluência comum para ocultar uma disfluência gaguejada.

O fato dos estudantes e fonoaudiólogos aqui pesquisados não apresentarem uma compreensão mais abrangente sobre o assunto, não significa, necessariamente, que estejam fora de sintonia com o tema. Há de se considerar que os sujeitos desta pesquisa não atuam predominantemente com linguagem. É importante registrar, também, que a linguagem é uma área ampla, que engloba vários outros temas e é a de menor número de profissionais com títulos de especialista no Brasil (dos 3.409 títulos concedidos pelo Conselho Federal de Fonoaudiologia, 16,13\% foram para Linguagem, 20,35\% para Voz, 31,12\% para Audiologia e 32,38\% para Motricidade Orofacial, conforme dados atualizados em 02/12/2006) ${ }^{41}$. Isso pode justificar, em parte, o distanciamento dos profissionais aqui pesquisados dos conceitos mais específicos de fluência e disfluência. É também necessário ressaltar que os textos que abordam fluência e disfluência no contexto da normalidade da fala estão mais ligados à lingüística ${ }^{5,9,18}$, devido à natureza epistemológica dessa ciência; na fonoaudiologia, esta discussão surge com maior força nos estudos e textos mais recentes ${ }^{3,7,13,42,43}$.

\section{CONCLUSÃO}

Neste estudo observou-se uma tendência dos sujeitos pesquisados, sem diferenças significantes entre estudantes e profissionais, em definir fluência pela negativa ou pela idealização de uma fala livre de rupturas e em conceituar disfluência como um sinal de alteração e não como fenômeno intrínseco à fala. Os anos de atuação tendem a modificar esses conceitos, mas, de maneira geral, permanece o mesmo entendimento.

A grande citação de termos relacionados à taxa de elocução (como "ritmo" e "velocidade da fala") parece sugerir que, para os sujeitos da pesquisa, a fluência e a disfluência estão fortemente relacionadas a variações desse aspecto da fala e que a taxa de elocução, e não as disfluências, seria o componente que mais afeta o grau de fluência.

Consideraram os fatores afetivos, principalmente ansiedade, como os que mais afetam a fluência, atribuindo uma influência secundária a fatores lingüísticos, cognitivos e genéticos.

Os tipos de disfluências normais e gaguejadas foram categorizados de forma alinhada com a literatura, mas os anos de atuação modificaram esse resultado, passando a classificar algumas disfluências normais como do tipo gaga. 


\begin{abstract}
Purpose: to check the understanding of current students (those who are in $3^{\text {rd }}$ and $4^{\text {th }}$ year) and Speech-Language Pathology professionals about the concepts of fluency and dysfluency, the components and aspects that affect fluency and the sorts of speech dysfluency. Methods: 107 questionnaires were applied in a sample of 57 professionals and 50 students of Speech-Language Pathology. Qualitative and quantitative analyses were applied to open questions and quantitative analysis was applied to multiple-choice questions. Results: more than 20 analytic factors were identified for each open answer, but no factor was mentioned by the great majority of subjects. Most cited fluency component was speech rate. Psychological factors such as anxiety and introversion-extraversion are among the more quoted factors that affect fluency level. The three sorts of dysfluency which were more categorized as stuttered were blocks, initial prolongations and defense behaviors. There were not significant statistical differences between students' and professionals' answers. Increase in professional practice has changed some answers. Conclusion: the subjects: 1) have revealed an ideal concept of fluency ("speech free from disruptions"), 2) have considered dysfluency as some kind of disorder and not as a speech inherent event, 3) have considered speech rate, not dysfluency, as fluency's most important component, 4) have considered psychological factors, mainly anxiety, as the factors that have the major impact on fluency level (language, cognitive and genetic factors would have a secondary importance) and 5) have classified dysfluency according to scientific literature.
\end{abstract}

KEYWORDS: Language; Stuttering; Concept Formation; Professional Practice

\section{REFERÊNCIAS}

1.Perkins WH. What is stuttering? J Speech Hear Disord. 1990; 55(3):370-82.

2.DSM-IV. Manual diagnóstico e estatístico de transtornos mentais. 4. ed. Porto Alegre: Artes Médicas; 1995.

3. Meira I. Abordagem fenomenológica da fluência. In: Ferreira LP, Lopes DMB, Limogi SCO. Tratado de fonoaudiologia. São Paulo: Roca; 2004. p. 1017-26. 4.Felsenfeld S, Kirk KM, Zhu G, Statham DJ, Neale MC, Martin NG. A study of the genetic and environmental etiology of stuttering in a selected twin sample. Behav Genet. 2000; 30(5):359-66.

5.Scarpa EM. Sobre o sujeito fluente. Cad Est Lingüíst. 1995; 29:163-84.

6.Perkins WH, Kent RD, Curlee RF. A theory of neuropsycholinguistic function in stuttering. J Speech Hear Res. 1991;34(4):734-52.

7.Merlo S. Hesitações na fala semi-espontânea: análise por séries temporais [mestrado]. Campinas (SP): Departamento de Lingüística, Universidade Estadual de Campinas; 2006.

8.Chambers $F$. What do we mean by fluency? System. 1997; 25(4):535-44.

9. Marcuschi LA. A hesitação. In: Neves MHM. Gramática do português falado. v. 7: novos estudos. Campinas: Humanitas e UNICAMP; 1999. p. 159-94.

10. Degiovani VM, Chiari BM, Schiefer AM. Disfluência: características dos tipos e freqüência de ocorrência em grupo de escolares. Pró-Fono R Atual Cient. 1999;
11(1):32-7.

11. Terminology Pertaining to fluency and fluency disorders: guidelines. ASHA Special Interest Division 4: Fluency and Fluency Disorders. ASHA Suppl. 1999; 41(2 Suppl 19):29-36.

12. Friedman S. A construção do personagem bom falante. São Paulo: Summus Editorial; 1994. 30 p.

13. Schiefer AM. Abordagem psicolingüística da fluência. In:Ferreira LP, Befi-Lopes DM, Limongi SCO, organizadoras. Tratado de fonoaudiologia. São Paulo: Roca; 2004. p. 1035-9.

14. Pereira MMB. Análise lingüística da gagueira. São Paulo: AM3 Artes; 2003. 24 p.

15. Andrade CRF. Diagnóstico e intervenção precoce no tratamento das gagueiras infantis. São Paulo: Prófono; $1999.112 \mathrm{p}$.

16. Pereira MMB, Ferrante C, Cohen C, Carvalho GGT. Análise da duração de consoantes na fala fluente de gagos. Rev Soc Bras Fonoaudiol. 2003; 8(2):14-8.

17. Wingate ME. Fluency and disfluency: illusion and identification. J Fluency Disord. 1987; 12:79-101. 18. Sousa e Silva MCP, Koch, IGV. Estratégias de desaceleração do texto falado. In: Kato MA, organizadora. Gramática do português falado. v. 5: Convergências. 2. ed. Campinhas: UNICAMP; 2002. p. 329-40.

19. Oliveira MHMA, Gargantini MBM. Comunicação e gagueira. Rev Est Psicol PUC-Campinas. 2003; 20(1):51-60.

20. Starkweather CW. Fluency and stuttering. New Jersey: Prentice-Hall; 1987.

21. Jakubovicz R. A gagueira: teoria e tratamento de 
adultos e crianças. Rio de Janeiro: Revinter; 1997.7 p. 22. Ribeiro IM. $O$ adolescente e a gagueira: noções básicas sobre a gagueira: suas características, sua etiologia e as teorias sobre sua natureza. In: Ribeiro IM, organizadora. Conhecimentos essenciais para atender bem a pessoa com gagueira. Coleção CEFAC. São José dos Campos: Pulso; 2003. p. 73-88.

23. Merlo S, Mansur LL. Disfluências normais durante a produção da linguagem oral em adultos. Relatório Final para FAPESP, 2000.

24. Lima PLC, Françozo E. Memória de trabalho e produção oral da linguagem. Cad Est Lingüíst. 2001; 40:93-105.

25. Messenger M, Onslow M, Packman A, Menzies R. Social anxiety in stuttering: measuring negative social expectancies. J Fluency Disord. 2004; 29(3):201-12.

26. Andrade CRF. Protocolo para avaliação da fluência da fala. Pró-Fono R Atual Cient. 2000; 12(2):131-4.

27. Campbell JH, Hill DG. Systematic disfluency analysis. In: Stuttering therapy. Northwestern University and Stuttering Foundation of America 1994; 51-75.

28. Andrade CRF. Fluência. In: Andrade CRF, BefiLopes DM, Fernandes FDM, Wertzener HF. ABFW: teste de linguagem infantil nas áreas de fonologia, vocabulário, fluência e pragmática. Carapicuíba (SP): Pró-Fono; 2000. p. 61-75.

29. Zackiewicz DV. Avaliação quantitativa e qualitativa das disfluências em indivíduos gagos e fluentes [mestrado]. São Paulo (SP): Universidade Federal de São Paulo; 1999.

30. Friedman S. Reflexões sobre a natureza e o tratamento da gagueira. In: Passos, MC, organizadora. Fonoaudiologia: recriando seus sentidos. Série interfaces. São Paulo: Plexus; 1996. p. 81-115. 31. Jubran CCAS, Koch IGV. Construção do texto falado. v. 1. Campinas: Editora UNICAMP; 2006.

32. Andrade CRF. História natural da gagueira: estudo II: sistema miofuncional oral e funções. Pró-Fono R Atual Cient. 2002; 14(3):361-70.
33. Bohnen AJ. Fatores de risco para o surgimento da gagueira: um estudo de caso dos dois anos e três meses aos doze anos e quatro meses. In: Meira I, organizadora. Tratando da gagueira: diferentes abordagens. São Paulo: Cortez; 2002. p. 25-40.

34. Ijuim JO. Terapia de grupo: uma alternativa de atendimento para gagueira. In: Meira I, organizadora. Tratando da gagueira: diferentes abordagens. São Paulo: Cortez; 2002. p.113-23.

35. Andrade CRF, Sepulcre AS, Romano MVR, Juste F, Sassi F. Percepção de pais de crianças gagas e fluentes sobre as características de temperamento de seus filhos. Rev Soc Bras Fonoaudiol. 2004; 9(4):205-11.

36. Ezrati-Vinacour R, Levin I. The relationship between anxiety and stuttering: a multidimensional approach.J Fluency Disord. 2004; 29(2):135-48.

37. Alm PA. Stuttering, emotions, and heart rate during anticipatory anxiety: a critical review. J Fluency Disord. 2004; 29(2):123-33.

38. Ratner NB, Sih CC. Effects of gradual increases in sentence length and complexity of children's dysfluency. J Speech Hear Disord. 1987; 52(3):278-87.

39. Buriel Y, Fombuena NG, Böhm P, Rodés E, PeñaCasanova J. Fluencia verbal. Estudio normativo piloto en una muestra española de adultos jóvenes (20 a 49 años). Neurologia. 2004; 19(4):153-9.

40. Butman J, Allegri RF, Harris P, Drake M. Fluencia verbal em español: datos normativos en Argentina. Medicina. 2000; 60:561-4.

41. Conselho Federal de Fonaoudiologia. Disponível em:URL: http://www.fonoaudiologia.org.br/index2.htm. 42. Friedman S. Fluência: um acontecimento complexo. In: Ferreira LP, Befi-Lopes DM, Limongi SCO, organizadoras. Tratado de fonoaudiologia. São Paulo: Roca; 2004. p. 1027-34.

43. Azevedo NP, Freire RM. Trajetórias de silenciamento e aprisionamento na língua: o sujeito, a gagueira e o outro. In: Friedman S, Cunha MC, organizadoras. Gagueira e subjetividade: possibilidades de tratamento. São Paulo: Artmed; 2001. p. 146-60.

RECEBIDO EM: 30/08/06

ACEITO EM: 21/02/07

Endereço para correspondência:

SMPW Quadra 27 conjunto 03 lote 05 casa D, Núcleo Bandeirante

Brasília-DF

CEP: $71745-703$

Tel: (61) 33386564 / 81117543

E-mail:anamariafono@yahoo.com.br

Rev CEFAC, São Paulo, v.9, n.1, 40-6, jan-mar, 2007 